\title{
Patient barriers to implantable cardioverter defibrillator implantation for the primary prevention of sudden cardiac death in patients with heart failure and reduced ejection fraction
}

Laura Lihua Chan ${ }^{1}$, MBBS, MRCP, Choon Pin Lim ${ }^{1}$, MBBS, MRCP, Soe Tin Aung ${ }^{2}$, MBBS, MMed, Paul Quetua ${ }^{1}$, MD, Kah Leng $\underline{H o}^{1}$, MBBS, MRCP, Daniel $\underline{\text { Chong }}{ }^{1}$, MBBS, MRCP, Wee Siong ${\underline{T e o^{1}}}^{1}$, MBBS, MRCP, David $\underline{\operatorname{Sim}}^{1}$, MBBS, MRCP,

Chi Keong Ching $^{1}$, MBBS, MRCP

INTRODUCTION Device therapy is efficacious in preventing sudden cardiac death (SCD) in patients with reduced ejection fraction. However, few who need the device eventually opt to undergo implantation and even fewer reconsider their decisions after deliberation. This is due to many factors, including unresolved patient barriers. This study identified the factors that influenced patients' decision to decline implantable cardioverter defibrillator (ICD) implantation, and those that influenced patients who initially declined an implant to reconsider having one.

METHODS A single-centre survey was conducted among 240 patients who had heart failure with reduced ejection fraction and met the ICD implantation criteria, but had declined ICD implantation.

RESULTS Participants who refused ICD implantation were mostly male (84\%), Chinese (71\%), married (72\%), currently employed (54\%), and had up to primary or secondary education (78\%) and monthly income of < SGD 3,000 (51\%). Those who were more likely to reconsider their decision were aware that SCD was a consequence of heart failure with reduced ejection fraction, knowledgeable of the preventive role of ICDs, currently employed and aware that their doctor strongly recommended the implant. Based on multivariate analysis, knowledge of the role of ICDs for primary prophylaxis was the most important factor influencing patient decision.

CONCLUSION This study identified the demographic and social factors of patients who refused ICD therapy. Knowledge of the role of ICDs in preventing SCD was found to be the strongest marker for reconsidering ICD implantation. Measures to address this information gap may lead to higher rates of ICD implantation.

Keywords: barriers, heart failure, implantable cardioverter defibrillator

\section{INTRODUCTION}

Numerous studies have shown the survival benefit of implantable cardioverter defibrillator (ICD) therapy for the primary prevention of sudden cardiac death (SCD) in patients with ischaemic ${ }^{(1-5)}$ and nonischaemic heart failure. ${ }^{(4,6,7)}$ The long term cost-effectiveness ratio of ICD therapy is also better than that of antiarrhythmic drug therapy. ${ }^{(8-10)}$ Thus, the American Heart Association (AHA), American College of Cardiology (ACC) and the Heart Rhythm Society (HRS) recommend ICD implantation for the primary prevention of SCD in patients who meet the specified criteria. ${ }^{(11)}$ Despite this recommendation, ICD implantation rates appear low in most areas. In the United States, a recent study at a tertiary hospital showed a $28 \%$ ICD implantation rate for the primary prevention of SCD. ${ }^{(12)}$ A study done in the Netherlands showed a dismal 7\% ICD implantation rate for primary prophylaxis; ${ }^{(13)}$ this is similar to an $8 \%$ estimate in a 2005 Guidant study involving patients in Western Europe ${ }^{(14)}$ and the $20 \%$ estimate in real world registry data from Germany. ${ }^{(15)}$ In Singapore, the implantation rate seems to follow this trend. This is despite the fact that numerous studies have shown that a higher ICD implantation rate was associated with a lower mortality rate. ${ }^{(16,17)}$ An internal audit performed at the National Heart Centre Singapore (NHCS) from January 2009 to June 2009 showed an ICD implantation rate of only slightly over $20 \%$.

A previous study showed that refusal of ICD implantation for primary prophylaxis was common and that it was mainly due to an underestimation of the risk of SCD and perceived lack of strength of the doctor's recommendation. ${ }^{(18)}$ However, to our knowledge, no prior study has replicated these findings in a healthcare setting similar to that in Singapore, which has a unique patient population. As such, the present study, which was conducted in a large-volume centre in Singapore, aimed to determine if demographic and social factors had any correlation with a patients' decision to decline the ICD implant.

\section{METHODS}

A descriptive cross-sectional survey was conducted among NHCS patients over a six-month period (October 2012 to March 2013). Eligible study participants were recruited from outpatient cardiology clinics or admissions/referrals to the cardiology wards.

${ }^{1}$ Department of Cardiology, National Heart Centre Singapore, ${ }^{2}$ Health Services Research, Eastern Health Alliance, Singapore 
They fulfilled the current ACC/AHA/HRS criteria for automatic ICD implantation for the primary prevention of SCD; ${ }^{(11)}$ had not previously had an ICD implantation; understood the English, Chinese or Malay language; and had declined their doctor's recommendation of ICD implantation. Only patients aged $\geq 21$ years and who were able to give written informed consent were finally included. Patients who were excluded fulfilled the criteria for secondary prevention of SCD (according to the ACC/ AHA/HRS guidelines); had an expected length of survival of less than one year; or were previously diagnosed with any form of depression or cognitive impairment. In line with the protocol, ethical approval from the centre's Institutional Review Board and written informed consent from each patient were obtained. Dedicated research coordinators were trained to administer the face-to-face survey in the English, Chinese or Malay language.

Participants were interviewed using a multiple-choice questionnaire (Appendix). The questions were derived from previous surveys, local practices and known patient issues with ICD implantation. Study variables assessed were: (a) patient demographics (age, gender, ethnicity, religion, nationality, level of education, occupation and current income level); (b) clinical data (heart failure aetiology and duration, comorbidities, mobility status, and number of previous outpatient clinic appointments/ hospitalisations and ICU admissions); (c) knowledge of heart failure with reduced ejection fraction, or perceived understanding of the consequences or outcomes of heart failure and methods of preventing SCD; (d) knowledge of device therapy (awareness of ICD functions and its lifestyle impact); and (e) patient barriers to ICD implantation, such as the perceived strength of the doctor's recommendation and other factors contributing to refusal to undergo ICD implantation.

The standard descriptive cross-sectional sample size equation determined sample size. The following estimations were made: (a) Type 1 error of 5\% (a p-value $<0.05$ indicated statistical significance); and (b) the estimated proportion of participants who were likely to agree to ICD implantation (based on a previous population estimate) was less than $20 \%$, giving a computed sample size of at least 236. A total of 240 eligible patients consented to participate in the study. All participants completed a face-to-face interview conducted by designated research coordinators using the standardised questionnaire. Other information, including patient demographics and medical history, was sourced from the participants' medical records. The association between considering ICD implantation, participants' demographic data, as well as knowledge of the disease and device (using likelihood ratios) was analysed. Multivariate analysis was performed to determine significant odds ratios (ORs) among the factors that showed a significant association. Analysis was carried out using IBM SPSS Statistics version 19.0 (IBM Corp, Armonk, NY, USA). A p-value $<0.05$ indicated statistical significance.

\section{RESULTS}

A total of 240 patients participated in the study. Patient demographics are shown in Table I. The mean age of the patients
Table I. Demographic information of the participants $(n=240)$.

\begin{tabular}{|c|c|}
\hline Characteristic & No. (\%) \\
\hline $\mathrm{Age}^{*}(y r)$ & $61.2 \pm 9.7$ \\
\hline \multicolumn{2}{|l|}{ Gender } \\
\hline Male & $202(84)$ \\
\hline Female & $38(16)$ \\
\hline \multicolumn{2}{|l|}{ Ethnicity } \\
\hline Chinese & $171(71)$ \\
\hline Malay & $39(16)$ \\
\hline Indian & $26(11)$ \\
\hline Others & $4(2)$ \\
\hline \multicolumn{2}{|l|}{ Marital status } \\
\hline Married & $173(72)$ \\
\hline Unmarried & $67(28)$ \\
\hline \multicolumn{2}{|c|}{ Employment status } \\
\hline Employed & $130(54)$ \\
\hline Unemployed & $110(46)$ \\
\hline \multicolumn{2}{|l|}{ Educational level } \\
\hline Up to primary & 94 (39) \\
\hline Above primary & $146(61)$ \\
\hline \multicolumn{2}{|l|}{ Monthly income } \\
\hline$<$ SGD 3,000 & $123(51)$ \\
\hline$\geq \operatorname{SGD} 3,000$ & $117(49)$ \\
\hline
\end{tabular}

*Data presented as mean \pm standard deviation.

Table II. Clinical data of the participants $(n=240)$.

\begin{tabular}{lc}
\hline Parameter & No. (\%) \\
\hline NYHA status & $112(47)$ \\
Class I & $111(46)$ \\
Class II & $17(7)$ \\
Class III & \\
Cause of heart failure & $167(70)$ \\
Ischaemic heart disease & $58(24)$ \\
Dilated cardiomyopathy & $15(6)$ \\
Others &
\end{tabular}

NYHA: New York Heart Association

was $61.2 \pm 9.7$ years. $84 \%$ of the patients were men, $71 \%$ were Chinese, $72 \%$ were married and only $54 \%$ were employed during their participation in the study. $39 \%$ received none or up to primary education, $39 \%$ received secondary education and $22 \%$ received tertiary education. The average monthly income in about half of the patient population was $<$ SGD 3,000. Ischaemic heart disease was the main cause of heart failure $(70 \%)$ and a majority of the 240 patients were of New York Heart Association functional class I or II (Table II). On average, the patients had three admissions for heart failure complications prior to the survey. All were ambulant except for one patient who was wheelchair-bound.

The most common perceived consequence of heart failure was stroke $(42 \%)$, followed by SCD $(28 \%)$ and heart attack $(17 \%) ; 14 \%$ of patients indicated that they did not know what the consequences were. About $68 \%$ of patients believed that medication alone could prevent SCD, while about $16 \%$ felt that it could be prevented by diet and exercise alone. Only a staggering 
Table III. Patient factors and their association with the patient's likelihood to reconsider having an implantable cardioverter defibrillator.

\begin{tabular}{|c|c|c|c|}
\hline \multirow{2}{*}{$\begin{array}{l}\text { Demographics/ } \\
\text { clinical factors }\end{array}$} & \multicolumn{2}{|c|}{ No. (\%) } & \multirow[t]{2}{*}{ p-value } \\
\hline & $\begin{array}{l}\text { Likely to } \\
\text { reconsider } \\
\text { (n= 85) }\end{array}$ & $\begin{array}{l}\text { Unlikely to } \\
\text { reconsider } \\
(n=155)\end{array}$ & \\
\hline Age* (yr) $^{*}$ & $59.9 \pm 9.9$ & $61.9 \pm 9.6$ & 0.088 \\
\hline Age group (yr) & & & 0.681 \\
\hline$<65$ & $56(36)$ & $98(64)$ & \\
\hline$\geq 65$ & $29(34)$ & $57(66)$ & \\
\hline Gender & & & 0.590 \\
\hline Male & $73(36)$ & $129(64)$ & \\
\hline Female & $12(32)$ & $26(68)$ & \\
\hline Ethnicity & & & 0.867 \\
\hline Chinese & $60(35)$ & $111(65)$ & \\
\hline Non-Chinese & $25(36)$ & $44(64)$ & \\
\hline Religion & & & 0.909 \\
\hline Buddhist & $35(35)$ & $65(65)$ & \\
\hline Others & $50(36)$ & $90(64)$ & \\
\hline Marital status & & & 0.826 \\
\hline Married & $62(36)$ & $111(64)$ & \\
\hline Unmarried & $23(34)$ & $44(66)$ & \\
\hline Educational level & & & 0.193 \\
\hline Up to primary & $38(40)$ & $56(60)$ & \\
\hline Above primary & $47(32)$ & $99(68)$ & \\
\hline Monthly income & & & 0.353 \\
\hline$<\mathrm{SGD} 3,000$ & $47(38)$ & $76(62)$ & \\
\hline$\geq \operatorname{SGD} 3,000$ & $38(32)$ & $79(68)$ & \\
\hline Occupation & & & 0.031 \\
\hline Employed & $54(42)$ & $76(59)$ & \\
\hline Unemployed & $31(28)$ & $79(72)$ & \\
\hline Disease duration (yr) & & & 0.710 \\
\hline$\leq 5$ & $52(36)$ & $91(64)$ & \\
\hline$>5$ & $33(34)$ & $64(66)$ & \\
\hline
\end{tabular}

* Data presented as mean \pm standard deviation

$8 \%$ understood the preventive role of ICDs for SCD. For $17 \%$ of patients, SCD was the most feared outcome of heart failure. The majority, however, felt otherwise; 37\% most feared being bedbound and $30 \%$ feared being breathless. A small minority were most afraid of chest pain ( $8 \%$ ) or indicated they did not know what outcome they feared most ( $8 \%$ ).

Almost all respondents (98\%) learned about ICDs solely from their doctors. Only a small proportion tried to gain additional knowledge from the Internet (5\%) and from publications (10\%). When asked about the function of ICDs, $52 \%$ correctly answered that they prevent SCD. The following were among the reasons for refusing an ICD, arranged based on frequency: high cost (27\%), invasive nature of the procedure (24\%), fear of complications $(11 \%)$ and advanced age (9\%). The majority $(61 \%)$ felt that they themselves were the most important person influencing their decision on whether to have the implant. Only $15 \%$ felt that doctors played a more important role in the decision. All the participants felt that an ICD would restrict their current lifestyle
Table IV. Comparison of patients' survey responses with the likelihood of reconsidering having an implantable cardioverter defibrillator (ICD).

\begin{tabular}{|c|c|c|c|}
\hline \multirow[t]{2}{*}{ Parameter } & \multicolumn{2}{|c|}{ No. (\%) } & \multirow[t]{2}{*}{ p-value } \\
\hline & $\begin{array}{l}\text { Likely to } \\
\text { implant } \\
(n=85)\end{array}$ & $\begin{array}{l}\text { Unlikely } \\
\text { to implant } \\
(n=155)\end{array}$ & \\
\hline $\begin{array}{l}\text { Knows SCD is most common } \\
\text { consequence of HF }\end{array}$ & & & 0.850 \\
\hline Yes & $24(36)$ & $42(64)$ & \\
\hline No & $61(35)$ & $113(65)$ & \\
\hline Knows ICDs prevent SCD & & & $<0.001$ \\
\hline Yes & $15(79)$ & $4(21)$ & \\
\hline No & $70(32)$ & $151(68)$ & \\
\hline $\begin{array}{l}\text { SCD is most feared HF } \\
\text { outcome }\end{array}$ & & & 0.019 \\
\hline Yes & $21(51)$ & $20(49)$ & \\
\hline No & $64(32)$ & $135(68)$ & \\
\hline $\begin{array}{l}\text { Knows main function of } \\
\text { ICDs }\end{array}$ & & & 0.270 \\
\hline Yes & $48(38)$ & $77(62)$ & \\
\hline No & $37(32)$ & $78(68)$ & \\
\hline $\begin{array}{l}\text { Perceived strength of } \\
\text { doctor's recommendation }\end{array}$ & & & 0.022 \\
\hline Strong & $25(49)$ & $26(51)$ & \\
\hline Others & $60(32)$ & $129(68)$ & \\
\hline
\end{tabular}

HF: heart failure; SCD: sudden cardiac death

in some way. These predicted restrictions included: inability to do heavy lifting (30\%), problems when handling electrical devices $(17 \%)$ or taking a plane $(10 \%)$, inability to swim $(12 \%)$, and issues when performing sexual acts (5\%).

At the end of the survey, participants were asked if they would reconsider undergoing an ICD implantation. Only 35\% expressed that they might agree to have the device in the future, while most (65\%) remained unwilling. Factors such as gender, religion, ethnicity, age, marital status, income, educational level or longer duration of the disease ( $>5$ years) did not seem to have an impact on whether participants would reconsider having the device. Participants who were actively employed (42\% vs. $28 \%, p=0.031$ ) (Table III), feared SCD the most (51\% vs. $32 \%$, $p=0.019)$, and knew that ICDs prevent SCD (79\% vs. $32 \%$, $\mathrm{p}<0.001$ ) were more likely to reconsider ICD implantation (Table IV). After multiple logistic regression analysis, only the variable of knowledge that ICDs could prevent SCD was independently associated with the likelihood of reconsidering undergoing ICD implantation (OR 6.197, 95\% confidence interval 1.899-20.227) (Table V).

\section{DISCUSSION}

This study sought to identify the demographic and social factors that predicted the likelihood of having an ICD implant in those who required the device. A previous study reported that demographic and social factors were significantly correlated with ICD implantation rates; however, it was conducted in the United States and had a very different population base from that 
Table V. Multivariate analysis of factors that showed a significant association.

\begin{tabular}{lrrrrr}
\hline Factor & $\begin{array}{l}\text { Odds } \\
\text { ratio }\end{array}$ & \multicolumn{2}{c}{$\mathbf{9 5 \%} \mathbf{C l}$} & p-value \\
\cline { 3 - 4 } & & $\begin{array}{c}\text { Lower } \\
\text { limit }\end{array}$ & $\begin{array}{c}\text { Upper } \\
\text { limit }\end{array}$ & \\
\hline Currently employed & 0.754 & 0.420 & 1.353 & 0.343 \\
Knows ICDs prevent SCD & 6.197 & 1.899 & 20.227 & 0.003 \\
Knows HFREF leads to SCD & 1.685 & 0.807 & 3.519 & 0.165 \\
Strong doctor's recommendation & 1.796 & 0.921 & 3.503 & 0.086 \\
\hline
\end{tabular}

$\mathrm{Cl}$ : confidence interval; HFREF: heart failure with reduced ejection fraction ICD: implantable cardioverter defibrillator; SCD: sudden cardiac death

encountered in the authors' local practice. ${ }^{(18)}$ To our knowledge, this was the first attempt to replicate the study in a large-volume centre in Singapore.

Based on the findings, factors traditionally linked with acceptance of more aggressive management (e.g. device therapy), such as better educational attainment, higher salary, longer disease duration and younger age, did not predict a lower likelihood of patients declining the ICD. Interestingly, the participants' current employment status was a predictor. This could be due to the fact that ICD implantation is costly and, hence, prohibitive in Singapore. The current cost of basic ICD implantation is about SGD 11,000 (approximately SGD 2,000 after government subsidy). This is on top of expenses incurred for various medicines for heart failure and other comorbidities. Unemployed patients with no stable source of income may decline to undergo the expensive procedure.

The patient's perception of the level of strength of doctor's recommendation was also a significant predictor. Patients who thought that their doctor was not firm in recommending an ICD implant (as an option vs. a necessity for primary prophylaxis) were less likely to agree to the procedure. This may also be a consequence of the participants' almost total reliance on their doctors for information regarding the ICDs $(98 \%$ relied on the patient-doctor encounter for ICD information). These patients mainly relied on the conveyed value of the device as presented by the physicians, although this perception may not reflect the actual strength of recommendation. Even after discussing and reaching a decision, most patients continued to harbour erroneous, preconceived notions (e.g. SCD can be completely avoided by medication, diet and exercise) that may have clouded their perception of the doctor's recommendation.

Not surprisingly, knowledge that heart failure with reduced ejection fraction is a risk for SCD and that ICDs help prevent SCD was a predictor for patients who intimated that they might have an ICD implant in the future. Unfortunately, despite having been educated by different healthcare providers, almost half $(48 \%)$ of the respondents were not aware that the key function of ICDs is preventing SCD, highlighting the fact that patients may not fully understand what their doctors tell them. Additionally, SCD was not the most feared consequence of heart failure with reduced ejection fraction, suggesting that this fact was not impressed upon those who initially refused the implant. This emphasises the importance of improving the way patients are educated prior to obtaining consent for device implantation, and the need for more validation that the patient fully understands the situation prior to obtaining their decision. This misunderstanding may be due to many factors: limited time for adequate doctor-patient encounters, language barriers (patients' differing capacities to understand the English language) or deep-seated beliefs that contradict the advice of their doctor, etc. Therefore, dedicated healthcare professionals who speak the patient's first language and can spend the necessary amount of time with the patient to explain may help improve the implantation rate, especially if device implantation is a major decision for the patient.

Following multivariate analysis, only knowledge that ICDs prevent SCD remained a strong predictor for the reconsideration of undergoing ICD implantation. This shows that those who previously refused the implant did not understand what they had refused and suggests that patients would reconsider if they can be made to understand.

There were some limitations to the study, including a low initial estimate of the percentage of patients who were expected to agree to an ICD implant (about 19\%), leading to a low computed sample size requirement. The initial estimate was based on a single six-month audit done in 2009 and hence may not be entirely representative. The study also did not include patients who accepted the offer of ICD implantation and subsequently had the implant, which could have provided a good control group. Also, the patients who said that they were likely to reconsider were not followed up on; thus, there is no data that they received an implant after the survey. The participants were also not further subdivided into inpatient and outpatient subgroups. Furthermore, the time spent with the doctor discussing the device was not recorded; doctors may have more time for explanation during an outpatient visit than during rushed bedside rounds; this could be used to determine if time spent explaining the device was a factor. Future research can help to clarify the issues not resolved by this study.

In conclusion, this study demonstrates that patients still have many misconstrued notions about heart failure and ICDs. It is important to address these gaps to allow the patient to make the correct decision about implantation. The demographic and social factors of the patients who refused ICD therapy were identified, and the following factors were associated with a higher likelihood of reconsidering having an ICD implant: being employed; knowing that heart failure with reduced ejection fraction is a risk factor for SCD and that ICDs prevent SCD; and believing that their doctor strongly recommended the device therapy. Among the four factors, knowledge that ICDs were effective in preventing SCD was the most predictive based on multivariate analysis. Measures to re-educate the patient and emphasise the role of ICDs in preventing early demise may help more patients to agree to the implant after initially declining it, hence improving the overall ICD implantation rate in Singapore.

\section{ACKNOWLEDGEMENT}

This study was sponsored by Medtronic International Ltd. 


\section{REFERENCES}

1. Moss AJ, Hall WJ, Cannom DS, et al. Improved survival with an implanted defibrillator in patients with coronary disease at high risk for ventricular arrhythmia. Multicenter Automatic Defibrillator Implantation Trial Investigators. N Engl J Med 1996; 335:1933-40.

2. Buxton AE, Lee KL, Fisher JD, et al. A randomized study of the prevention of sudden death in patients with coronary artery disease. Multicenter Unsustained Tachycardia Trial Investigators. N Engl J Med 1999; 341:188290.

3. Moss AJ, Zareba W, Hall WJ, et al; Multicenter Automatic Defibrillator Implantation Trial II Investigators. Prophylactic implantation of a defibrillator in patients with myocardial infarction and reduced ejection fraction. N Engl J Med 2002; 346:877-83.

4. Bardy GH, Lee KL, Mark Db, et al; Sudden Cardiac Death in Heart Failure Trial (SCD-HeFT) Investigators. Amiodarone or an implantable cardioverter-defibrillator for congestive heart failure. N Engl J Med 2005; 352:225-37.

5. Greenberg H, Case RB, Moss AJ, et al; MADIT-II Investigators. Analysis of mortality events in the Multicenter Automatic Defibrillator Implantation Trial (MADIT-II). J Am Coll Cardiol 2004; 43:1459-65.

6. Desai AS, Fang JC, Maisel WH, Baughman KL. Implantable defibrillators for the prevention of mortality in patients with nonischemic cardiomyopathy: a meta-analysis of randomized controlled trials. JAMA 2004; 292:2874-9.

7. Kadish A, Dyer A, Daubert JP, et al; Defibrillators in Non-Ischemic Cardiomyopathy Treatment Evaluation (DEFINITE) Investigators. Prophylactic defibrillator implantation in patients with nonischemic dilated cardiomyopathy. N Engl J Med 2004; 350:2151-8.

8. Mark DB, Nelson CL, Anstrom KJ, et al; SCD-HeFT Investigators. Costeffectiveness of defibrillator therapy or amiodarone in chronic stable heart failure: results from the Sudden Cardiac Death in Heart Failure Trial (SCD-HeFT). Circulation 2006; 114:135-42.

9. Mushlin Al, Hall WJ, Zwanziger J, et al. The cost-effectiveness of automatic implantable cardiac defibrillators: results from MADIT. Multicenter Automatic Defibrillator Implantation Trial. Circulation 1998; 97:2129-35. 10. Zwanziger J, Hall WJ, Dick AW, et al. The cost effectiveness of implantable cardioverter-defibrillators: results from the Multicenter Automatic Defibrillator Implantation Trial (MADIT)-II. J Am Coll Cardiol 2006; 47:2310-8.

11. Tracy CM, Epstein AE, Darbar D, et al. 2012 ACCF/AHA/HRS focused update of the 2008 guidelines for device-based therapy of cardiac rhythm abnormalities: a report of the American College of Cardiology Foundation/ American Heart Association Task Force on Practice Guidelines. J Am Coll Cardiol 2012; 60:1297-313.

12. Bradfield J, Warner A, Bersohn MM. Low referral rate for prophylactic implantation of cardioverter-defibrillators in a tertiary care medical center. Pacing Clin Electrophysiol 2009; 32:S194-7.

13. Borleffs CJ, Wilde AA, Cramer MJ, Wever E, Mosterd A. Clinical implementation of guidelines for cardioverter defibrillator implantation: lost in translation? Neth Heart J 2007; 15:129-32.

14. John Camm A, Nisam S. European utilization of the implantable defibrillator: has 10 years changed the 'enigma'? Europace 2010; 12:1063-9.

15. Vester E, Stellbrink C, de Haan F; for the CRediT investigators. Low penetration of device therapy in CRT/ICD indicated patients and long term outcome. Results from the CRediT heart failure registry. Eur Heart J 2008; 29:816.

16. Parkes J, Chase DL, Grace A, Cunningham D, Roderick PJ. Inequity of use of implantable cardioverter defibrillators in England: retrospective analysis. BMJ 2005; 330:454-5.

17. Israel CW. Do some implant too many defibrillators or others too few? Europace 2009; 11:982-4.

18. Yuhas J, Mattocks K, Gravelin L, et al. Patients' attitudes and perceptions of implantable cardioverter-defibrillators: potential barriers to appropriate primary prophylaxis. Pacing Clin Electrophysiol 2012; 35:1179-87. 


\section{APPENDIX}

\section{QUESTIONNAIRE}

\section{Knowledge of heart failure with reduced ejection fraction}

A. Which is the most common consequence for heart failure with reduced ejection fraction patients?
1) Stroke
2) Sudden cardiac death
3) Heart attack
4) Cancer
5) Don't know

B. What can you do to prevent sudden cardiac death in heart failure with reduced ejection fraction?
1) Medicine
2) Diet and exercise
3) Traditional medicine
4) Implantable cardioverter defibrillator (ICD)
5) Don't know

C. What is the most feared symptom/consequence of heart failure in your personal opinion?
1) Breathlessness
2) Chest pain
3) Sudden cardiac death
4) Being bed-bound
5) Don't know

\section{Knowledge of ICDs}

A. Have you ever heard of an ICD?
1) Yes
2) No

B. Where did you hear about the ICD?
1) Doctors
2) Pamphlets and brochures
3) Family
4) Friends
5) Internet
6) Newspapers/magazines
7) Others

C. What is the key function of an ICD?
1) Prevent sudden cardiac death
2) Improve symptoms of breathlessness
3) Increase a slow heart rate
4) Others

D. What is your primary concern against an ICD?
1) Invasive procedure
2) High cost
3) Old age
4) Complications/side effects
5) Lack of information
6) Others

E. Who is the most important person influencing your decision on ICD implantation?
1) My doctors
2) My partner
3) My children
4) My friends
5) Myself
6) Others

F. What do you think are the lifestyle restrictions that you might face after an ICD implantation?
1) Cannot swim
2) Cannot take a plane
3) Cannot use microwave
4) Cannot undergo MRI
5) Cannot lift heavy things
6) Cannot use electrical products
7) Will affect sexual activity
8) Others

G. How much do you think you should pay for the ICD implantation after subsidy (in SGD)?
1) $\leq 500$
2) 501-1,000
3) $1,001-2,000$
4) $2,000-3,000$
5) 3,000-5,000
6) Others

\section{Physician's recommendations}

A. Has your doctor advised you to have this ICD device implanted for the treatment and prevention of the complications of your existing heart disease?
1) Yes
2) No

B. In your personal opinion, how strong was your doctor's recommendation to have an ICD implanted?
1) Strongly recommended
2) Recommended
3) Not recommended
4) Strongly discouraged
5) Cannot remember/not sure

C. Why do you think you need the ICD device implanted?
1) My heart function is poor and I am at risk of sudden death
3) I don't know why I need it
2) My doctor told me it was good for me
4) Others; please specify:

D. How likely would you agree to have the ICD implanted if your doctor recommended it again to you?
1) Definitely
2) Probably
3) Probably not
4) Definitely not
5) Not sure 